
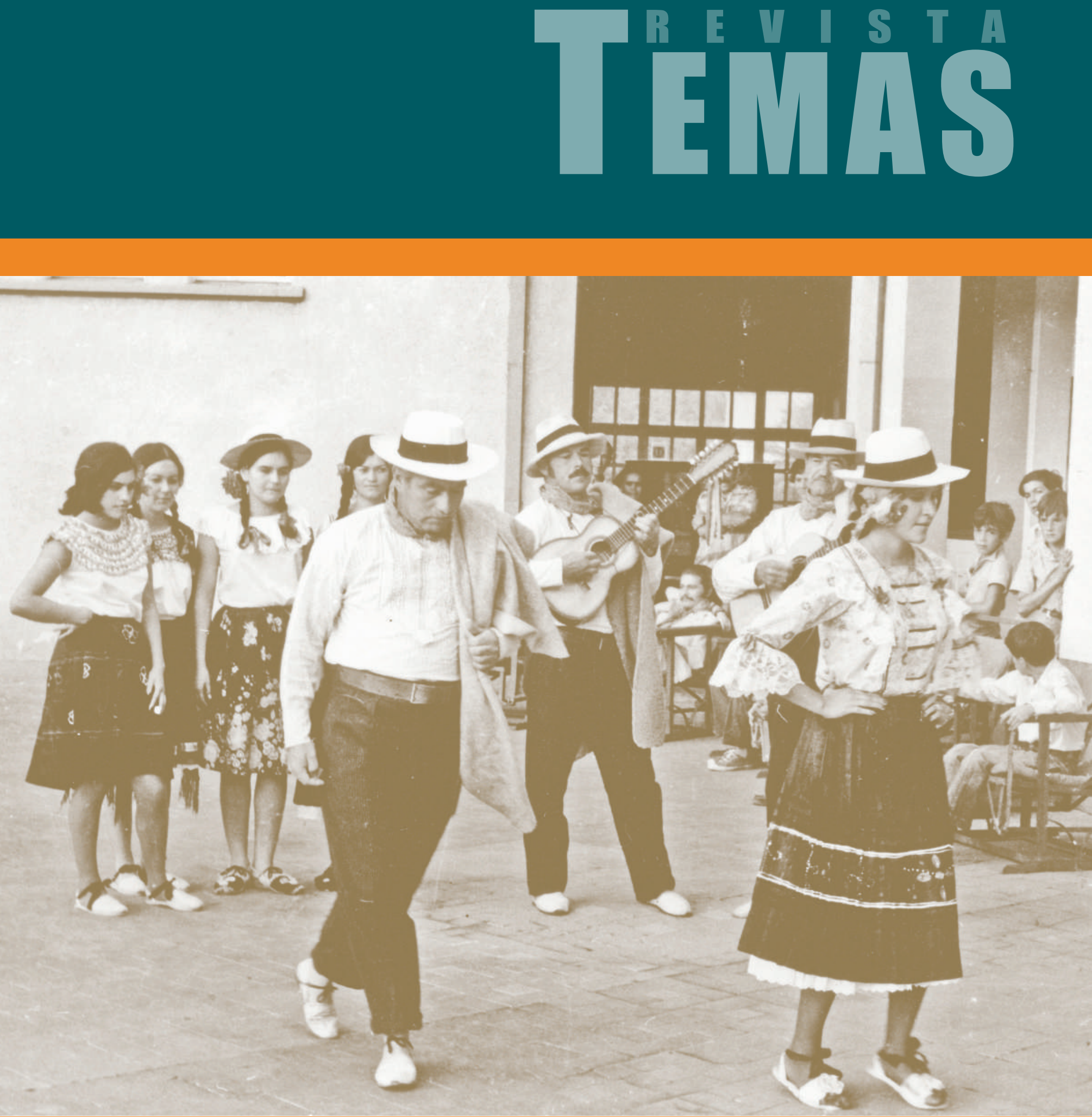



\title{
LA RELACIÓN GUERPO Y MOVIMIENTO EN LIBROS DE TEXTO DE EDUGACIÓN INFANTIL DE 1996 Y 2012
}

(Recepción: Julio 15 de 2013- Aceptación: Agosto 27 de 2013)

Vladimir Martínez Bello*

Álvaro Hernández Bello**

\section{Resumen}

Los libros de texto participan en el proceso de reproducción y transmisión directa o indirecta de modelos de comportamiento social, normas y valores. El objetivo del presente estudio consiste en comparar la forma en que se representa la relación cuerpo y movimiento en las imágenes de un libro de texto publicado en 1996 y otro publicado en 2012 pertenecientes al mismo grupo editorial y dirigido al sistema educativo infantil (Pre-Jardín). Para el estudio de las imágenes se utilizó la técnica de análisis de contenido con base en un sistema de categorías previamente establecido. Los dos libros de texto a pesar de ser publicados con una diferencia de diez y seis años, presentan los siguientes elementos comunes: Igualdad de presencia de los géneros masculino y femenino; señalan principalmente cuerpos infantiles con representación racial blanca; y finalmente, los dos libros de texto no representan ningún cuerpo con algún tipo de discapacidad. A su vez, los dos libros de texto se diferencian respecto a la ubicación del cuerpo en el espacio y los niveles de actividad motriz implícitos en las imágenes. Aunque en las categorías usadas para el análisis del cuerpo ninguna está relacionada con la categoría de clase social, es posible inferir que las relaciones hegemónicas que se manifiestan en las representaciones cotidianas de los cuerpos se han desarrollado en el país hacia un reconocimiento diferenciado de las diferencias de género, raza y discapacidad en una escala que va de mayor reconocimiento en cuanto al género a un menor reconocimiento en el asunto de la discapacidad. La forma como las dimensiones de Cuerpo y Movimiento estudiados, con sus respectivas categorías fueron abordadas, permite notar distintas configuraciones de imaginarios sociales, lo que contribuye al ejercicio de la crítica que corresponde a profesores y demás profesionales relacionados con la enseñanza.

\section{THE RELATIONSHIP BETWEEN BODY AND MOVEMENT IN GHILDHOOD EDUCATION TEKTBOOKS OF 1996 AND 2012}

\begin{abstract}
Alsstract
Textbooks are involved in the process of reproduction and direct or indirect transmission of social behavior patterns, norms and values. The aim of this study is to compare the way the relationship between body and movement are represented in the images of a textbook published in 1996 and another published in 2012 belonging to the same publishing group and addressed to the children's educational system (Pre-K). For the study of the images, the content analysis technique was used based on a system of categories previously established. Despite being published with a gap of sixteen years both textbooks have the following common elements: Equal presence of male and female bodies; they show mainly Caucasian children's bodies; and finally, none of the textbooks shows a body with any type of disability. In turn, the textbooks are different in terms of the location of the body in space and motor activity levels implied by the images. Although none of categories used for body analysis is related to social class, it is possible to infer that the hegemonic relations that occur in everyday representations of bodies have been developed in the country with a view to a distinct recognition of the differences of gender, race and disability on a scale from greater recognition of gender to a minor recognition in terms of disability. The way the Body and Movement dimensions studied, with their respective categories were addressed allows us to notice different social imaginary settings, contributing to the exercise of criticism that corresponds to teachers and other professionals involved in teaching.
\end{abstract}

\section{Kevwords}

Housing, Early education, Textbooks, Movement

\footnotetext{
1 Artículo de investigación en la línea de investigación titulada "La presencia del cuerpo infantil en la Escuela" desarrollada en la Facultat de Magisteri de la Universitat de Valencia, España. Inició en enero de 2013 y finalizó en mayo de 2013.

* Doctor en Ciencias de la Actividad Física y del Deporte (2011). Universitat de Valencia. España.vladimir.martinez@uv.es

** Magister en Estudios Culturales. Universidad Javeriana. alhernandez@unisalle.edu.co
} 


\section{Introducción}

En el ámbito de la pedagogía de la cultura física el interés por conceptualizar el concepto del cuerpo ha sido una prioridad para elaborar procesos de enseñanza-aprendizaje que luchen contra los distintos tipos de discriminación presentes dentro y fuera de la escuela. Por ejemplo, David Kirk (2002) señala que el concepto de cuerpo supera la simple visión biológica para hablar del cuerpo también como una construcción social y cultural, donde la ausencia de una reflexión crítica sobre los fenómenos sociales profundiza la incomprensión de las dinámicas relacionales que lo constituyen como un hecho social. Las representaciones que se tienen sobre las formas corporales dominantes, el papel de la mujer y la distorsión de la indisoluble integridad de la especie humana pueden convertirse en modelos dominantes presentes en el currículum escolar tanto dentro como fuera de las aulas (Terrón y Cobano, 2008; Devís y Pérez, 2009). Ese proceso de legitimación cultural corporal se ha embebido no sólo de procesos educativos formales al interior de la educación física escolar, sino en aquellos espacios (dentro como fuera de la escuela) donde el cuerpo es objeto de representaciones y performatividades sociales (Kirk, 2007; Chacón, 2010).

El currículum es una construcción social y cultural (Gimeno, 1991; Giroux, 1992) no se puede menos que asegurar que los materiales didácticos pueden participar en el proceso de condicionamiento de la relación cuerpo y movimiento. A su vez, se ha señalado que los materiales curriculares transmiten significados tanto en las aulas como fuera de ellas que condicionan la forma de comprender el cuerpo y sus posibilidades de movimiento (Molina, Devis y Peiro, 2008). El libro de texto es considerado como un medio central de aprendizaje compuesto por texto e imágenes destinados a alcanzar un conjunto específico de resultados educativos (Brugelles y Cromer, 2009) que contribuyen a la adquisición de conocimiento sobre las ciencias, las artes, la literatura y además, que participan en el proceso de transmisión directa o indirecta de modelos de comportamiento social, normas y valores (Sacristán, 1991; Maestro, 2002; Brugelles y Cromer, 2009). Los libros de texto y, en general, los materiales escolares pueden ser perfectamente estudiados y considerados como dispositivos que representan los intereses de una sociedad, razón por la cual se constituyen como modelos de formas de pensar (Selander, 1990). Las imágenes de los libros de texto son el elemento que más llama la atención de los niños y son especialmente importantes en las primeras etapas de la escuela -infantil y primaria-, pues actúan como elementos motivadores y reforzadores de valores e ideas (Selander, 1990). Sin embargo, en los últimos años, se ha señalado que las imágenes tanto de libros de texto como de otros materiales curriculares, reproducen, trasmiten y refuerzan ideologías dominantes respecto a la representación de la capacidad corporal, los estereotipos de género y la diversidad corporal que señalan diferentes modalidades en las que el cuerpo que se vincula con la escuela, así como las dinámicas en las que puede llegar a ser silenciado o excluido (Weitzman, Eifler, Hokada y Ross, 1972; Turner, 1996; González, 2005; Taboas \& Rey, 2012).

Uno de los objetivos de las Organizaciones Internacionales frente a la lucha contra las manifestaciones de exclusión social presentes en el sistema educativo ha sido poner de manifiesto cómo los materiales curriculares se convierten en elementos reforzadores de los estereotipos de género, de representación racial o diversidad corporal presentes en las aulas educativas. Por 
ejemplo, la Organización de las Naciones Unidas para la Educación, la Ciencia y la Cultura (UNESCO) (2009) ha centrado su atención respecto al análisis de los libros de texto desde la igualdad de género. De esa forma, se señala por una parte, la necesidad de la comunidad académica de mostrar cómo la desigualdad de género es construida en los materiales curriculares y así ofrecer alternativas a la compresión de los significados dominantes y las formas de contrarrestarlos.

Por otra parte y con la intención de poner de manifiesto cómo las falsas representaciones raciales atentan contra el principio de no discriminación por razones de origen, la $\mathrm{V}$ Declaración sobre la raza y los prejuicios raciales aprobada por la Conferencia General de la ONU, exhorta a los Estados y en ellos a la comunidad educativa para que los libros de texto den cabida a nociones éticas de diversidad humana para abolir la discriminación de carácter racial con el fin de evitar que sean transmitidas a los niños (UNESCO, 1978). Respecto a la integración de la diversidad corporal en las aulas educativas a través de los principios de escuela inclusiva, la Organización Mundial de la Salud (OMS) (2011) en las últimas décadas ha señalado que uno de los principales obstáculos que enfrentan las personas con discapacidad en el sistema educativo son las creencias, prejuicios y estereotipos de la población general y que una forma, parte de la base de la creación "de un entorno de aprendizaje inclusivo" que ayude a los niños a aprender y realizar su potencial, con gran responsabilidad del papel que cumplen los materiales curriculares en la transmisión de estos significados.

En Colombia, la Constitución Política de 1991 y el desarrollo legislativo del derecho a la educación contemplado principalmente en la Ley 115 de 1994 garantizan a todas las personas sin distinción alguna a ejercer el derecho constitucional a recibir una educación integral. La educación inicial en Colombia se define en el artículo 15 de la Ley General de Educación (Ley 115 de 1994) como "la ofrecida al niño para su desarrollo integral en los aspectos biológico, cognoscitivo, sicomotriz, social y espiritual, a través de experiencias de socialización, pedagógicas y recreativas". De igual manera, uno de los objetivos específicos de la etapa infantil consiste en "el conocimiento del propio cuerpo y de sus posibilidades de acción, así como la adquisición de su identidad y su autonomía" (Artículo 16, Ley 115 de 1994) y la generación de procesos de identificación y reconocimiento de procesos de aprendizaje con el entorno, como base para la construcción de valores, actitudes y comportamientos (Decreto 2247 de 1997). Para los objetivos del presente estudio, seguimos el documento "Colombia por la primera infancia" (Política pública por los niños y niñas, desde la gestación hasta los 6 años), elaborado por el Gobierno Colombiano (2006); cabe señalar que en este documento se asumen indistintamente los conceptos de educación inicial y educación para la primera infancia para referirnos a la educación que va desde el nacimiento hasta los 6 años y que se corresponden con el primer contacto de los niños y niñas con en el sistema educativo. Por esa razón, el Ministerio de Educación Nacional de Colombia motivado por la necesidad de regular la producción de libros de texto ha desarrollado directrices para asegurar la calidad de los mismos (NTC ICONTEC, 2000), así como la construcción de lineamientos en el cumplimiento del ejercicio del derecho a la educación (MEN, 2001). Para el año 2000 , las instancias gubernamentales se habían limitado al establecimiento de unas directrices formales más no sustanciales de los requerimientos de los libros de texto. Fue entonces a partir del año 2000 que se crearon unos lineamientos para 
el diseño y construcción de manuales escolares.

Con base en este sustento normativo, tanto los actores educativos como los programas y proyectos curriculares, deben fundamentarse en los principios y fines anteriormente descritos que garanticen el derecho a la educación de todos los niños, niñas y jóvenes sin distinción alguna en todo el sistema educativo colombiano.

Como sostienen distintos autores, el cuerpo en el sistema educativo de la primera infancia es un cuerpo que debe ser alimentado, cuidado e higienizado, pero donde se echan de menos elementos culturales y sociales que condicionan la construcción de ese mismo cuerpo (Vaca, 2005; Richter y Vaz, 2008). Si se parte de la base que los libros de textos son vehículos de socialización, se hace necesario reflexionar sobre su contenido, así como de los significados que se transmiten para contribuir a los conocimientos, valores y demás, anteriormente nombrados (Montagnes, 2000). A pesar de la literatura existente sobre la reproducción de significados en los libros de texto en otras áreas de conocimiento y grados escolares (Terrón y Cobano, 2009; Taboas y Rey, 2012; Hardin \& Hardin, 2004) no existen estudios sobre la representación del cuerpo infantil en libros de texto de educación inicial que busquen responder a la pregunta de cómo se construye la relación cuerpo y movimiento en las imágenes de dos libros publicados en dos periodos de tiempo, uno de 1996 y el otro del año 2012. Esta investigación está motivada por la obligación de analizar la forma en que evolucionan los significados de las imágenes dirigidos a población infantil, no sólo a nivel colombiano e internacional, sino también por la voluntad de iniciar la discusión crítica de los significados que están presentes en las aulas de educación inicial.

\section{Metodología}

El análisis de contenido fue realizado sobre imágenes del cuerpo infantil de dos libros de texto de educación inicial de los grados de Pre-Jardín del Grupo Editorial Norma. El primer libro de texto fue publicado en 1996 (Luna Lunera 1) y el segundo fue publicado en 2012 (Consentidos B). Los criterios utilizados para la selección de este libro de texto fueron: Nivel de Pre-Jardín; publicado Colombia y en castellano; con presencia de la editorial en los tres grados de la educación inicial; editada e impresos con posterioridad a la Constitución Política de Colombia de 1991. El análisis de contenido se basa principalmente en la elaboración de un sistema de categorías que son aplicadas en el análisis de, en nuestro caso, las imágenes donde se representa el cuerpo infantil. La elaboración del sistema de categorías ha tenido como referencia estudios previos realizados en el ámbito del análisis de contenido de libros de textos (Maureen \& Barbara, 2010; Taboas y Rey, 2012) con modificaciones especiales al sistema educativo infantil. Se utilizaron dos dimensiones: Cuerpo y Movimiento. Las categorías para la dimensión Cuerpo fueron: género, representación racial, discapacidad e indumentaria. Las categorías para la dimensión Movimiento fueron: espacio y nivel de actividad motriz. Se consultó a dos expertos y éste fue reelaborado. Tres observadores analizaron las imágenes y se aplicó el índice Kappa de Fleiss. A continuación, se utilizaron los estadísticos chi-cuadrado, razón de verosimilitud $y$ el coeficiente de contingencia con el objetivo de encontrar diferencias significativas. Se utilizó el programa estadístico SPSS versión 19. 


\section{Resultados}

\section{Género-agrupación}

Figura 1. Representación del género

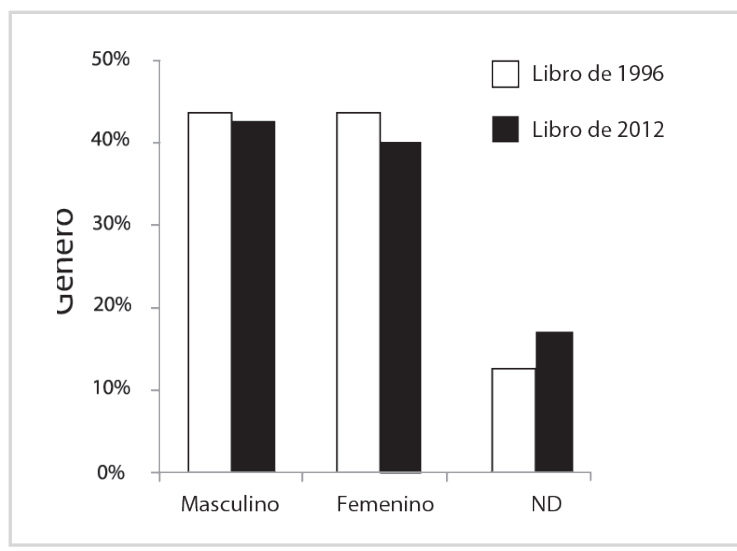

Fuente: Autor

En la Figura 1 se representa el Género en las imágenes de los dos libros de texto. En ambos libros de texto se representan de forma similar los distintos indicadores de la variable Género. Se estudió la dependencia entre la variable Año de publicación y Género y no se encontró dependencia entre ellas. Por tanto, la igualdad en la representación de niños y niñas no depende del año de publicación de los dos libros de texto.
Figura 2. Representación del género-agrupación

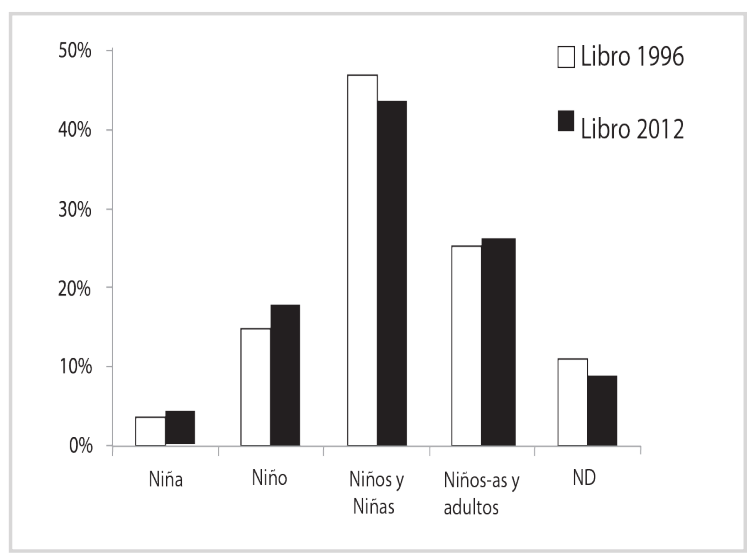

Fuente: Autor

En la Figura 2 se observa la distribución de los distintos indicadores de la variable Género-Agrupación y se observa que el indicador Grupos de niños y niñas obtuvo el $46 \%$ en el libro de 1996 y $45 \%$ en el libro de 2012. Se observa una distribución estadísticamente significativa entre los indicadores de la variable edad para cada libro de texto. Se estudia la dependencia entre las variables Año de publicación y Género-agrupación y no se observó una relación estadísticamente significativa. 


\section{Representación racial}

Figura 3. Representación racial

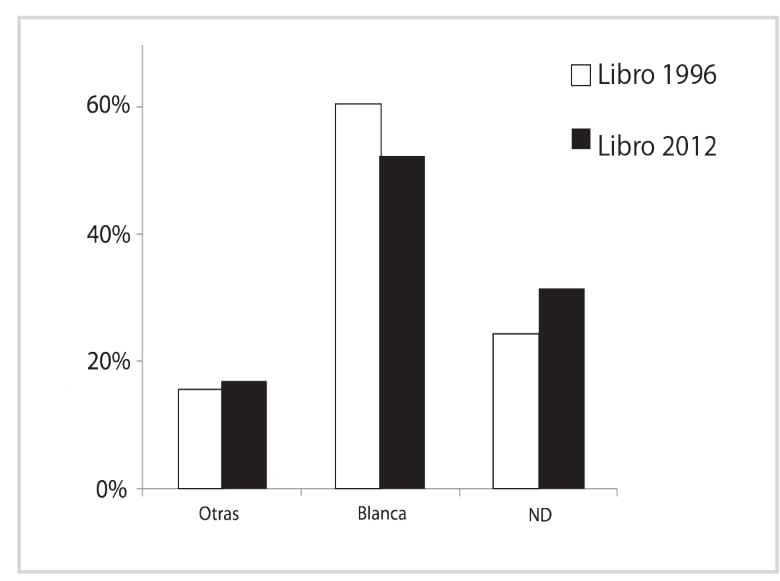

Fuente: Autor

En la Figura 3 se observa el porcentaje promedio de la variable Representación racial para los dos libros de texto. El $60 \%$ para el libro de 1996 y el $52 \%$ para el libro de 2012 representan el indicador Blanca, seguido del indicador Otras con un $16 \%$ y $17 \%$, respectivamente. El indicador otras, para el libro de texto de 1996 correspondió a un 5\% del indicador Mestiza, un 9\% para el indicador Negra, y un $2 \%$ para el indicador Indígena. Para el libro de texto de 2012, el indicador Otras, correspondió a un $13 \%$ del indicador Mestiza, seguido de un 2\% del indicador Negra, Asiática e Indígena respectivamente. En el $24 \%$ de las imágenes para el libro de 1996y 31\% para el libro de 2012, no es posible distinguir la representación racial. Se encuentra una distribución estadísticamente significativa entre los distintos indicadores de la variable Representación racial para los dos libros de texto. Se estudió la dependencia, entre las variables Año de publicación y Representación racial y no se observó una relación estadísticamente significativa. Es decir, los distintos niveles de la variable Representación racial no dependen del año al cual pertenecen los libros de texto analizados.

\section{Discapacidad}

Figura 4. Representación de la discapacidad

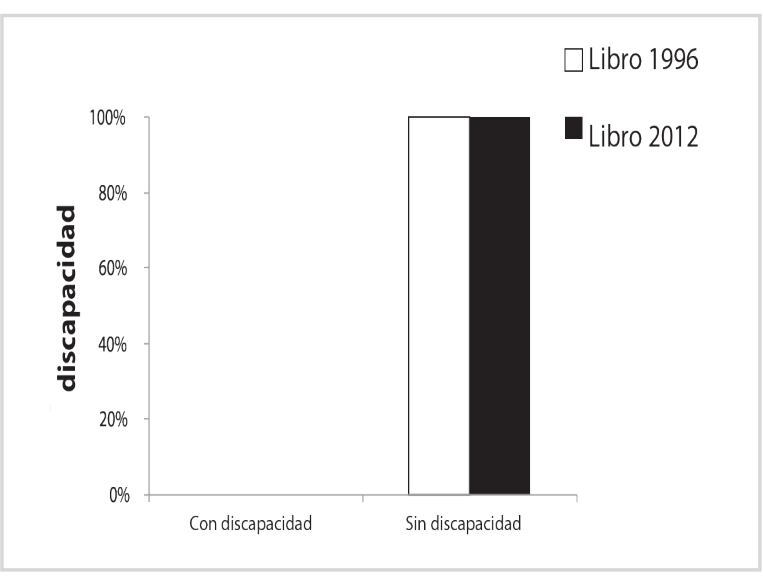

Fuente: Autor

En la Figura 4 se observa que de los 102 cuerpos de niños y niñas representados en los dos libros de texto se representan únicamente cuerpos sin discapacidad. La clasificación de los tipos de discapacidad se ha realizado siguiendo la clasificación en el ámbito educativo de la cultura física elaborado por Ríos (2003) a saber: discapacidad física, mental y sensorial, así como las disposiciones legislativas colombianas. No existió dependencia entre la variable Tipo de libro y Discapacidad. Es decir, los distintos niveles de la variable Discapacidad no dependen del año al cual pertenecen los libros de texto analizados. 


\section{Indumentaria}

Figura 5. Representación de la indumentaria

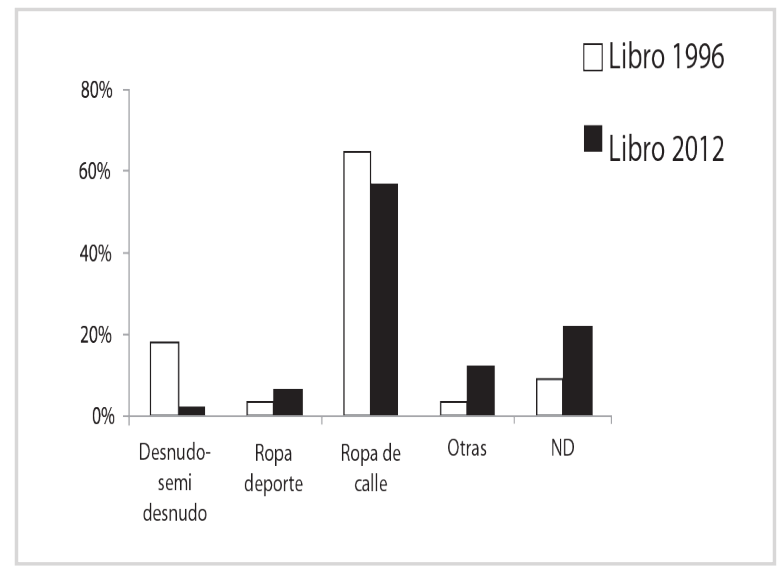

Fuente: Autor

En la Figura 5 se observa el porcentaje promedio de la variable Indumentaria para los dos libros de texto. El $65 \%$ para el libro de 1996 y el $57 \%$ para el libro de 2012 representan el indicador Ropa de calle El resto de indicadores se distribuye de manera uniforme en el resto de indicadores, salvo el indicador Desnudosemidesnudo, que para el libro de 1996 representa el $19 \%$ de las imágenes mientras que para el libro de 2012 éste correspondió al $2 \%$. Se observa una distribución estadísticamente significativa entre los indicadores de la variable Indumentaria para cada libro de texto. Se estudia la dependencia entre las variables Año de publicación e Indumentaria y no se observó una relación estadísticamente significativa.

\section{El cuerpo en el espacio}

Figura 6. Representación del espacio

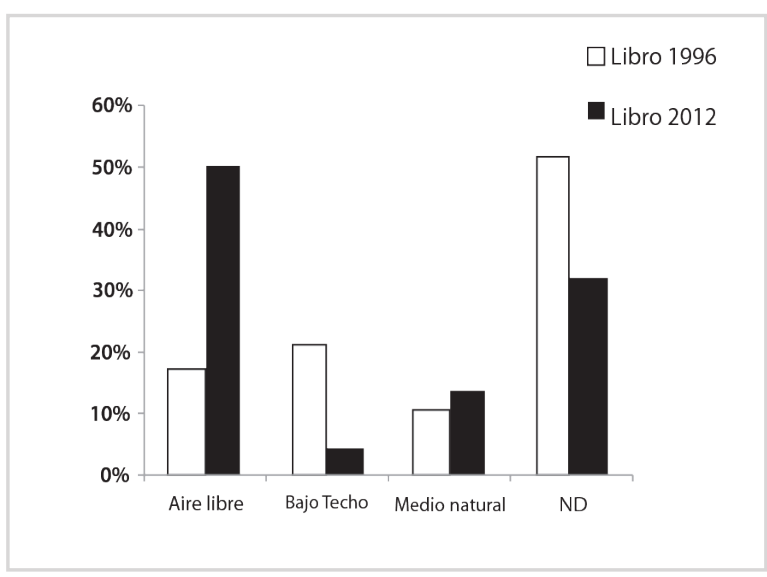

Fuente: Autor

En la Figura 6 se representa la ubicación de los cuerpos infantiles en el espacio. En el libro de texto de 2012 el indicador con mayor presencia es al Aire libre, con el $50 \%$, seguido del indicador no se distingue con el $32 \%$. Por el contrario, para el libro de texto de 1996, el indicador con mayor presencia es No se distingue, con el $52 \%$, mientras que el mismo indicador para el libro de texto de 2012 correspondió al $32 \%$. Se observa una distribución estadísticamente significativa entre los indicadores de la variable edad para los dos libros de texto. Se estudió la dependencia entre las variables Año de publicación y Espacio y se observó diferencia significativa. Es decir, los distintos niveles de la variable Espacio dependen del año al cual pertenecen los libros de texto analizados. 
Nivel de actividad motriz

Figura 7. Representación del nivel de actividad motriz

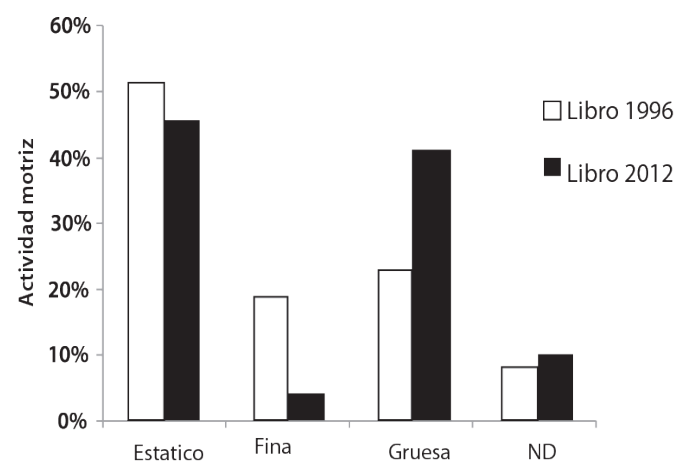

Fuente: Autor

En la Figura 7 se representa el Nivel de actividad motriz y se observa que el indicador Estático en el libro de texto de 1996 corresponde al $51 \%$ de las imágenes, mientras que el indicador motricidad gruesa correspondió al $23 \%$ y el indicador Motricidad Fina corresponde al 18\%. En el libro de texto de 2012 el indicador con mayor representación fue Estático con el 45\%, el indicador Motricidad gruesa con el $41 \%$, mientras que el indicador Motricidad fina corresponde al $4 \%$ de las imágenes. Se observa una distribución estadísticamente significativa entre los indicadores de las variables Nivel de actividad motriz para los dos libros de texto. Se estudió la dependencia entre las variables Año de publicación y Nivel de actividad motriz y se observó una diferencia estadísticamente significativa $(p<0.05)$. Es decir, los distintos niveles de la variable Nivel de actividad motriz dependen del año al cual pertenecen los libros de texto analizados.

\section{Discusión}

Se ha señalado que los materiales curriculares transmiten significados tanto dentro como fuera de las aulas educativas (Molina et al, 2008; Devís y Pérez, 2010), convirtiéndose éstos en herramientas que ofrecen una mirada de la estructura social y cultural de la sociedad que influyen en la formación del conocimiento de sí mismo, de los otros y del mundo en general (Güemes y Área, 1994). De la evidencia científica actual tanto a nivel nacional como internacional, no existen estudios que comparen cómo se representa la relación cuerpo y movimiento en libros de textos de educación inicial en periodos de tiempo diferentes, razón por la cual consideramos importante continuar en el estudio de la transmisión de significados de los materiales curriculares que llegan al aula de educación inicial.

Para facilitar la discusión de los resultados éstos serán analizados por cada una de las categorías en las dos dimensiones: Cuerpo y Movimiento.

\section{Dimensión Cuerpo}

\section{Representación del género}

La comunidad académica y las Organizaciones Internacionales han señalado que para promover la igualdad en el sistema educativo se deben fomentar actitudes por parte del profesorado para desentrañar significados que transmiten los materiales curriculares desde una perspectiva de igualdad entre hombres y mujeres (UNESCO, 2009). Con este objetivo, se ha creído conveniente comparar si existe un equilibrio en la representación de los niños en las imágenes de libros de texto editados y publicados con 15 años de diferencia y dirigidos al mismo segmento poblacional. Tal como se observa en la Figura 1, existió una representación equilibrada del género masculino y femenino en ambos 
periodos de tiempo. Debido a la escasa literatura sobre la representación de los géneros en libros de textos de educación inicial en Colombia y en el extranjero, se ha apoyado nuestra discusión en libros de texto de educación primaria y secundaria, especialmente españoles, con resultados contrarios a los encontrados por nosotros. Por ejemplo, Terrón y Cobano (2009) observaron una representación muy baja del género femenino en libros de texto españoles en educación primaria del área de conocimiento del medio, matemáticas y lengua, así como en libros de texto marroquíes dirigidos al mismo segmento poblacional. A su vez, Pellejero y Torres (2011) analizaron la presencia de mujeres en libros de texto de matemáticas y de conocimiento del medio en el primer curso de Educación Primaria utilizados en una Comunidad Autónoma española y encontraron que éstas solamente fueron representadas el $37.2 \%$ de las veces, a diferencia de los hombres, que lo fueron un $62.8 \%$. Por último, similar resultado ha sido observado en libros de texto de educación física en primaria y secundaria donde se refuerza el protagonismo masculino en las imágenes (Moya, Ros, Bastida y Menescardi, 2013; Taboas, y Rey, 2012), así como otros materiales curriculares (Weitzman et al., 1972; Kortenhaus y Demarest, 1993). En otros materiales curriculares como cuentos infantiles se ha estudiado si el paso del tiempo ha permitido visibilizar de forma equilibrada a mujeres y hombres. Del célebre estudio realizado por Weitzman et al. (1972) quienes encontraron que los hombres fueron representados en las imágenes más del doble de veces que las mujeres, en un estudio más reciente Oskamp, Kaufman y Wolterbeek (1996) reportaron en cuentos infantiles una mayor representación de la mujer. Estos últimos, señalan que si se parte de la base que en los libros se asume una postura donde se quieren alcanzar unos modelos sobre un comportamiento femenino determinado, un aumento de la representación de mujeres es bienvenida, en la medida en que su ausencia puede posibilitar que las niñas al observar los textos vean disminuido el sentido de sí mismas. Una razón que puede explicar esta diversidad de resultados se debe a la forma de seleccionar el material curricular, el número de imágenes, así como las áreas educativas de los libros de texto. En definitiva, los libros de texto colombianos de educación inicial en dos periodos de tiempo diferentes en el nivel de pre-jardín demuestran un equilibrio de niños y niñas.

\section{Representación racial}

Tal como sostiene la UNESCO (1978), los estudios sobre la diversidad corporal, el origen étnico y las características físicas y fisiológicas deben analizarse desde el entendimiento de la unidad intrínseca de la especie humana. Es decir, todos los seres humanos pertenecen a la misma especie, tienen el mismo origen, y donde cualquier otra perspectiva debe ser condenada. Según los resultados encontrados, en la Figura 3 , se observa que independientemente del año de publicación, el indicador con mayor presencia es la representación racial blanca. Otras representaciones como negra, indígena, mestiza y asiática no alcanzan en ninguna de las editoriales el $15 \%$. En general, al observar la combinación de distintas representaciones raciales en ningún libro de texto ésta alcanza el 20\%. En Colombia, pero utilizando textos escolares dirigidos a población distinta a la de la primera infancia, Soler (2009) al analizar textos escolares de ciencias sociales de dos editoriales pertenecientes a la primaria y a la secundaria, concluyó que, a pesar de la inexistencia de un discurso de racismo explícito, en los textos escolares se observan formas sutiles donde se representa a los blancos y a los 
mestizos como integrantes de la identidad nacional colombiana y una tendencia a la homogeneización y etnocentrismo blanco a expensas de otros grupos minoritarios, como por ejemplo los afro-colombianos y los indígenas. Recientemente, Yáñez (2012) llegó a la misma conclusión en textos escolares de ciencias sociales en Colombia, en donde concluye que los indígenas y afro-colombianos sólo se les menciona en relación con aspectos geográficos, históricos y estadísticos sin hacer referencia a aporte alguno en la vida cultural, social y económica del país.

De la misma forma, la representación racial también ha sido estudiada en textos escolares en otros países, como es el caso de España. Por ejemplo, González et al. (2010) observaron en libros de texto de educación física en secundaria durante la vigencia de dos leyes orgánicas de educación en el sistema español (1990-2006), que la representación racial blanca en las imágenes fue mayor comparada con otras representaciones raciales en ambos periodos de tiempo. Similar resultado ha sido observado por Moya et al. (2013) en libros de texto de educación física para el tercer ciclo de primaria, donde el indicador raza blanca correspondió al $46 \%$ de las imágenes, mientras que otras representaciones correspondió al $20 \%$.

En definitiva, las imágenes de dos libros de texto pertenecientes al mismo grupo editorial, uno publicado en 1996 y otro en 2012, señalan la representación racial blanca como dominante, a expensas de otras, como la mestiza, la negra o la indígena que son silenciadas a pesar de la diversidad que muestra la realidad cultural colombiana tanto actual como pasada.

\section{Representación de la discapacidad}

El sistema educativo tiene la obligación de reducir las diferencias que por motivos de diversidad social, económica y corporal, entre, se encuentran presentes en las aulas. Bajo esa misma perspectiva, la OMS (2011) ha señalado que uno de los grandes retos respecto a la integración de las personas con algún tipo de discapacidad, es la reducción de los estereotipos y prejuicios que tiene la población general sobre la diversidad física, mental y sensorial de la población.

Para los efectos de este estudio, entendemos la discapacidad tal como lo establece en Colombia la Ley 1098 de 2006 Código de la Infancia y la Adolescencia. De esa manera, se entiende por discapacidad, la limitación física, mental, sensorial o cualquier otra, temporal o permanente de una persona para realizar actividades esenciales de la vida cotidiana. Según datos del Censo de 1993 (Departamento Nacional de Estadística, Colombia) aproximadamente el $2 \%$ de la población colombiana para aquella época tenía algún tipo de limitación. De ellos, un gran porcentaje $(89.7 \%)$ de niños y jóvenes con algún tipo de limitación no asistía al sistema educativo. Con estadísticas más recientes, en 2005, alrededor del $2 \%$ de los niños menores de 5 años presentaba algún tipo de discapacidad y cuya situación se agrava en niños de grupos socioeconómicos más pobres (Documento CONPES Social 109, 2007)

De los resultados arrojados por nuestro estudio, se observa una total ausencia de cuerpos con algún tipo de limitación en los dos libros de textos analizados (Figura 4). Es decir, existe un cuerpo infantil dominante que se observa en las imágenes y una completa inexistencia de cuerpos diversos. Si las previsiones del Plan Sectorial de Educación 2006-2010 elaborado por el Gobierno Colombiano 
se cumplieron, y decimos se cumplieron porque no se cuenta con las estadísticas actuales, el $80 \%$ de estudiantes con necesidades educativas especiales ingresaron al sistema educativo infantil (Revolución Educativa, Plante Sectorial de Educación, 2006). Sin embargo, este gran reto señalado en 2006, el libro de texto destinado a niños de pre-jardín publicado en el año 2012 no representa ningún niño con alguna necesidad educativa especial. De esta forma, a pesar de los grandes avances que se hacen en el ejercicio del derecho a la educación de todos los niños y niñas en Colombia, los libros de texto no representan esa diversidad. A pesar de la inexistencia de estudios que analicen las imágenes en libros de texto en educación inicial, tanto a nivel colombiano como internacional, nos apoyaremos para elaborar la discusión de resultados de otros niveles educativos, así como de otras áreas de conocimiento. En el ámbito de la educación física tanto en Estados Unidos como en España, se ha reportado una muy baja representación de personas con discapacidad en las imágenes de libros de texto (Hardin y Hardin, 2004; Taboas y Rey, 2012). Para Hardin y Hardin (2004), las implicaciones prácticas y los mensajes embebidos en las imágenes ausentes es una manifestación del reforzamiento de las estructuras sociales que privilegian a un cuerpo físicamente capacitado a expensa de individuos con discapacidades.

Según el informe sobre discapacidad de la OMS (2011), una forma de abordar los obstáculos y desigualdades en el sistema educativo, parte de la base de la creación "de un entorno de aprendizaje inclusivo" que ayude a los niños a aprender y realizar su potencial, con gran responsabilidad del papel que cumplen los materiales curriculares en la transmisión de estos significados. En la literatura actual, a pesar de la fundamental importancia que tienen los materiales curriculares en la transmisión de significados, así como el valor que tiene como referente de comportamiento y valores sociales, no existen estudios que analicen cómo se construyen los distintos cuerpos en las imágenes de libros de texto dirigidos a niños de educación inicial. Para luchar frente a esto se requiere no sólo identificar y eliminar las barreras dentro y fuera de la escuela, sino también modificar las falsas representaciones que frente a nuestro caso se tiene sobre cuerpos tradicionales aptos frente a cuerpos no tradicionales, invisibles y no aptos. A pesar de que La Ley 115 de 1994 señala que los establecimientos educativos organizarán acciones pedagógicas terapéuticas que permitan el proceso de integración académica y social de los educandos, para lograr de esta manera convertir a la escuela tradicional en escuela inclusiva los resultados arrojados por el presente estudio, se considera que la ausencia de cuerpos diversos a la cultura hegemónica en los libros de texto, profundiza en la discriminación y la desigualdad, e impide que los cuerpos diversos sean vistos como cuerpos integrados que pueden aprender, disfrutar y formarse integralmente.

\section{Representación de la indumentaria}

Distintos autores señalan que el vestido o la indumentaria son elementos cargados de significados sobre las características de los individuos, la clase social, la edad, la sexualidad y demás, donde a través de ellos se reconoce no sólo como un retrato del orden social sino también como una práctica corporal (Santiago, 2005; Zambrini, 2010). Por esa razón, determinar la forma en que se representa la indumentaria en los libros de texto, podría generar un espacio de análisis que complemente que el cuerpo se construye como elemento cultural en 
dos periodos diferentes. De los cuerpos representados en las imágenes, en los dos libros de texto, tanto el de 1996, como el de 2012, se observa con mayor proporción un cuerpo vestido con ropa de calle $65 \%$ y $57 \%$, respectivamente (Figura 5). El resto de indicadores se representan de forma similar con valores menores del $20 \%$. De esta forma, con una diferencia de 15 años en la edición y publicación de dos libros de texto, los cuerpos infantiles se encuentran vestidos con ropa habitual de forma indistinta tanto dentro como fuera de la escuela.

\section{Dimensión Movimiento}

\section{Representación del espacio}

Son distintos los factores que condicionan el concepto del cuerpo infantil en el sistema escolar. Por ejemplo, David Kirk (2007) señaló recientemente que la escolarización contemporánea ha influido en la construcción de la identidad corporal a través de la relación que existe entre el espacio y el tiempo en el sistema escolar, donde se configuran una serie de rituales de organización y de relaciones de poder. Según Chacón (2010), el cuerpo infantil es fácilmente impresionable al estímulo del orden visual de la arquitectura, que da lugar a determinadas formas de relación y comunicación que influyen en su comportamiento porque los espacios transmiten su disciplina al movimiento corporal. De los datos arrojados por nuestro estudio, se observa que mientras en el libro de texto de 1996, no es posible distinguir la ubicación del cuerpo en un espacio determinado, en el libro de 2012, en casi el $50 \%$ de las imágenes los cuerpos se ubican en espacios al aire libre (Figura 6). Es decir, las imágenes del libro más reciente al señalar al cuerpo infantil en espacios como calles, parques y plazas, creemos que ofrecen un mayor toque de realidad que podría identificar que el cuerpo se construye en contacto con la realidad, natural, social o cultural. Por ejemplo, Bajo (2001) señala que el conocimiento del paisaje como elemento cultural, no solamente debe hacer referencia a la comprensión de fenómenos geográficos, es decir, más allá de la idea de paisaje como sinónimo de vista panorámica, sino también como producto de los fenómenos sociales sobre el territorio, donde el paisaje se entiende como resultado de la acción de la sociedad sobre el medio. Como asegura el mismo autor, la percepción y comprensión del paisaje de los niños es producto de la sincronización entre los datos sensoriales y motrices, donde adquiere conciencia de la posición que ocupa su cuerpo en el entorno. El entorno, por tanto, sería interpretado bien físicamente, o bien por la percepción de la representación de los cuerpos en un medio determinado que transmiten las imágenes. Según Muñoz y Runge (2005) acerca de las intencionalidades de los espacios escolares en la formación o represión, las imágenes de los libros de textos analizados, permiten indagar sobre un marcado carácter de construcción del cuerpo en contacto son el medio natural más allá de la presencia corporal en el aula tradicional.

Por otra parte, Weitzman et al. (1972) señalaron en cuentos infantiles que la ubicación del cuerpo masculino se relacionaba con espacios abiertos, mientras el cuerpo femenino con espacios internos. Bajo ésta línea, Chacón (2010) señala que la ubicación del cuerpo femenino está asociado con lo pasivo, débil, inferior y privado, mientras que lo masculino con lo activo, fuerte, superior y público. Por ejemplo, en libros de texto de educación primaria, Terrón y Cobano (2008) han encontrado que la mujer se vincula con el entorno privado, mientras que un gran porcentaje relaciona a los hombres con el entorno público. Recientemente, Taboas y Rey (2012) 
concluyeron de las imágenes de libros de textos de educación física que la mujer realiza actividades estéticas de forma más habitual al estereotipo del ámbito privado de la mujer. Sin embargo, en nuestro estudio no se observa dependencia del género y la ubicación del cuerpo en el espacio y se concluye que no hay desequilibrio sobre los espacios que deben ocupar los niños y niñas.

\section{Representación del nivel de actividad motriz}

Los materiales curriculares son dispositivos de transmisión de significados (Molina et al., 2008) y éstos ejercen un papel protagónico sobre la forma de ver el mundo, el cuerpo y la forma que tiene el cuerpo de interactuar con el entorno, es fundamental conocer en qué medida los niveles de movimiento representados en las imágenes señalan posibilidades que el cuerpo o cuerpos pueden asumir. Por ejemplo, Vaca (2007) ha descrito distintas formas de presencia corporal que difieren de la situación educativa en el aula de educación inicial como por ejemplo, cuerpo implicado, cuerpo silenciado, cuerpo instrumentado, cuerpo objeto de tratamiento educativo y cuerpo objeto de atención. Por esa razón, hemos analizado cuál es el nivel de actividad motriz representado en las imágenes en los dos libros de texto y de esa forma señalar cómo la presencia corporal en el ámbito infantil a través de un material curricular es construida.

Como se observa en la Figura 7, mientras que para ambos libros de texto en casi el $50 \%$ de las imágenes el cuerpo infantil asume una posición estática, el porcentaje de incremento de compromiso motriz en el libro más reciente supera en el doble las actividades de motricidad gruesa comparado con el libro de 1996, así como una disminución en la implicación en actividades de motricidad fina para el libro publicado en 2012.
Por otra parte, muchos autores han descrito al cuerpo dentro del sistema educativo, como un dispositivo normalizador de control y poder al interior de las aulas educativas (Barbero, 2005), que se refuerza como señala Chacón (2010) a través de la percepción de los más pequeños acerca de sus posibilidades físicas y su relación con el género, donde los niños asumen un androcentrismo que atraviesa de forma silenciosa las prácticas educativas muchas veces sin la intención deliberada por parte del profesorado. Por ejemplo, Moctezuma (2011) en un análisis comparativo sobre la representación del cuerpo infantil en manuales escolares para la educación primaria en México, señala que después de clase, los niños acuden al patio de recreo donde podían "jugar", así como que las imágenes muestran a niñas saltando a la cuerda mientras los niños a jugar con pelotas de varios tamaños. Es en el patio escolar el sitio donde pueden jugar, correr y saltar, donde se observa una distinción entre espacio y tiempo para el juego y para el trabajo. De la misma forma señala la autora, los rituales sobre higiene y cuidado del cuerpo se practicaban en el hogar. En definitiva, los espacios en los cuales el cuerpo infantil, en libros de primaria, son la escuela y el hogar, donde cada uno de ellas estaba compuesto por reglas especiales. Una diferencia resaltada por la autora consiste en que la población a la que iban dirigidos los libros de texto del siglo XIX y el XX, era que el primero hacia gran hincapié en el medio urbano a expensas de representación desfavorable del niño rural, indígena o pobre como ejemplos de los males de la sociedad, mientras que en los más actuales, se modifica para educar también al niño que vivía en el campo.

En definitiva, el libro de texto de 1996 señala una muy baja implicación motriz de los cuerpos infantiles, mientras que el libro de texto más actual (2012) 
representa un cuerpo que puede asumir no solo una posición estática sino también actividades con gran componente motriz. Si relacionamos la variable espacio con el nivel de actividad motriz, se concluye que el cuerpo representado en las imágenes más actuales vincula el proceso educativo y la relación escuela y entorno de una forma más cercana a la realidad en la que viven los niños. Tal como apunta Schanragrodzky (2007) la resignificación del cuerpo y de sus posibilidades frente al espacio y al movimiento, se convierten en una necesidad de las actuales prácticas educativas para mostrar alternativas, por ejemplo, a la obsesión por las posiciones corporales en el sistema escolar, especialmente a la posición de estar sentados, relacionados con valores como la rectitud, el orden y el control corporal se parte de la base que el movimiento fomenta la construcción de la identidad de los más pequeños, la ausencia de imágenes donde el cuerpo humano está en movimiento, podría sostener cierta connotación de control y represión a expensas de la libertad que promueve el hecho de moverse.

\section{Conclusiones}

Fueron las teorías marxistas las que en un principio dominaron la interpretación de la escuela como un aparato ideológico del Estado que reflejaba en tanto que superestructura, la base económica que en última instancia constituía las relaciones sociales. Este tipo de teorías dieron paso a estudios importantes sobre el papel que tienen las instituciones educativas y sus planes y materiales concomitantes, en la reproducción del orden social dominante.

Así, fueron las teorías de la reproducción las que dominaron la interpretación social del escenario educativo. Con la crítica al estructuralismo, muchos análisis se trasladaron al análisis de la forma como se configuraban subjetividades a partir de discursividades que no siempre lograban ver la escala de intervención de la hegemonía en las particularidades de subjetividades específicas. Se dio, entonces, un vuelco a análisis de interpretación libre de corte cualitativo que no siempre fue validado por datos concretos que describieran contextos específicos. La crítica, entonces, se dio por sentada y se buscó su reproducción a escalas distintas que mostraran una variedad de objetos de estudio analizados con las mismas herramientas y se llegara a las mismas conclusiones.

Sin desconocer este panorama, se optó por partir de un análisis estadístico concreto sobre la recurrencia de las representaciones corporales en dos textos escolares no sólo con el fin de renovar el diálogo entre metodologías de corte cualitativo y cuantitativo sino para complementar la crítica con el dato que permite mostrar tendencias y recurrencias. En este sentido es muy importante mostrar la forma diferenciada como se representan los cuerpos y notar los modos diferentes en los que se realizan exclusiones o inclusiones que dan cuenta de imaginarios sociales y culturales.

Este tipo de estudios, contribuyen a la contextualización de análisis estadísticos en el planteamiento de debates donde pueden concurrir varias disciplinas. De hecho, puede ser modelo para el diseño de estudios que permitan a psicólogos y pedagogos cognitivos plantear las formas de representación distintas según la etapa de desarrollo cognitivo y los efectos que puede tener este tipo de representaciones (en un estadio del espejo por ejemplo) en la relación que establecen los niños y niñas con su propio cuerpo y el de los demás.

Es común encontrar concepciones de los textos escolares como dispositivos 
acabados, entidades discretas que se resisten no sólo a la interpretación sino a la reapropiación de sus contenidos. En tanto que hechos sociales, los textos escolares también son porosos, susceptibles de intervenciones e interpretaciones que los descolocan de sus lugares de enunciación. La forma como las dimensiones de Cuerpo y Movimiento estudiadas, con sus respectivas categorías, fueron abordadas, permiten notar distintas configuraciones de imaginarios sociales, donde, por ejemplo, el tema de género se ve desplazado por el de raza y el de discapacidad en tanto que una igualdad en la representación de los géneros no necesariamente implica un reconocimiento de otras diferencias humanas.

Todo esto quiere decir que las ideas y los hechos se mueven a velocidades distintas. Como dispositivos de representación, los textos escolares no sólo dan cuenta de la reproducción de un orden social dominante, sino también de las reivindicaciones sociales que se han realizado y han sido incluidas en el orden del discurso. Los avances en equidad de la representación del género, por ejemplo, no necesariamente se corresponden con hechos que los pongan por obra, aun cuando son más fáciles de adaptar a un orden social dominante que reivindicaciones raciales o la inclusión de capacidades diferentes. Corresponde pues a estudios siguientes, considerar la forma como las diferencias en la representación corporal indican también una transformación en los imaginarios sociales sobre el cuerpo (el propio y el del otro) y la manera como estas transformaciones en la representación dan cuenta de transformaciones reales en las relaciones sociales, o por el contrario, cómo estas últimas se resisten y conviven (a veces sin problema alguno) con ideas más progresistas.

\section{Referencias}

Asamblea Nacional Constituyente. (1991). Constitución Política de Colombia. Bogotá: Imprenta Nacional.

Bajo, M. (2001). “El paisaje" en el curriculum de educación primaria, dentro del área del conocimiento del medio natural, social y cultural. Aula: Revista de Pedagogía de la Universidad de Salamanca, (13), 51-61. España.

Barbero González, J. (2005). La escolarización del cuerpo: Reflexiones en torno a la levedad de los valores del capital "cuerpo" en educación física. Revista Iberoamericana De Educación, (39), 25-52. Madrid: $\mathrm{OEI}$

Brugelles, C., \& Cromer, S. (2009). In UNESCO (Ed.), Promoting gender equality through textbooks. A methodological guide. (1st ed.). France: United Nations Educational, Scientific and Cultural Organization.

Casas, N. (2012). Consentidos B. Bogotá Voluntad.

Chacón, K. (2010). El cuerpo infantil en la comunicación escolar. Madrid: Universidad Complutense de Madrid.

Colombia. (1993) Departamento Nacional de Estadística. Censo Nacional 1993. Bogotá: DANE

Colombia. (1994). Ley 115 de 1994. Ley General de Educación. Bogotá: Imprenta Nacional.

Congreso de la República de Colombia. (1997). Ministerio de Educación Nacional. Decreto 2247 de 1997. Bogota: El Ministerio.

Congreso de La República de Colombia. (2006) Ley 1098 de 2006. Código de la Infancia y la Adolescencia. Bogotá: Imprenta Nacional.

Departamento Nacional de Planeación. (2007). Documento CONPES Social 109. Política Pública Nacional de Primera infancia. Bogotá: El Departamento.

Devís, J. y Pérez, V. (2009) La ética profesional en la formación del profesorado de educación física. En L. Martínez y R. Gómez (Coords.) La educación física y el deporte en la edad escolar. El giro reflexivo en la enseñanza (pp.101-126). Buenos Aires: Miño y Dávila.

Gimeno, J. (1991). El curriculum, una reflexión sobre la práctica ( $3^{\mathrm{a}}$ ed.). Madrid: Morata.

Giroux, H. (1992). Teoría y Resistencia En Educación: Una Pedagogía para la Oposición. México: Editorial Siglo XXI.

González, A., Taboas, M. y Rey, A. (2010). Los libros de texto como herramientas para la promoción de una práctica físico-deportiva en igualdad: análisis comparativo de la representación racial entre los libros publicados durante la vigencia de la LOGSE y la LOE. Cuadernos de psicología del deporte, 10(3), 31-36. Logroño, España: Dialnet. 
González, M. (2005). ¿Tienen sexo los contenidos de la educación física escolar? Transmisión de estereotipos de sexo a través de los libros de texto en la etapa de secundaria: Transmisión de estereotipos de sexo a través de los libros de texto en la etapa de secundaria. Revista Internacional de Medicina y Ciencias de la Actividad Física y del Deporte, (18)

Güemes, R. y Área, M. (1994). Libros de texto y desarrollo del currículo en el aula: Un estudio de casos. La Rioja: Dialnet.

Hardin, B. \& Hardin, M. (2004). Distorted Pictures: Images of Disability in Physical Education Textbooks. Adapted Physical Activity Quarterly. Revista inclusiva. 21(4).

Kirk, D. (2002). The Social Construction of the Body in Physical Education and Sport. In Laker, Anthony (Ed.). The Sociology of Physical Education and Sport: An Introductory Reader (pp. 79-91) London: Taylor \& Francis

Kirk, D. (2007). Con la escuela en el cuerpo, cuerpos escolarizados: La construcción de identidades ínter/nacionales en la sociedad postdisciplinaria. Agora para la Educación Física y el Deporte, (4), 39-56. Valdivia: Agora

Kortenhaus, C. \& Demarest, J. (1993). Gender role stereotyping in children's literature: An update. Sex Roles, 28(3-4), 219.

Maestro, P. (2002). Libros escolares y curriculum: Del reinado de los libros de texto a las nuevas alternativas del libro escolar. Revista De Teoría y Didáctica De Las Ciencias Sociales, (7)

Maureen, J. \& Barbara, J. (2010). Coloring within the lines: Gender stereotypes in contemporary coloring books. Sex Roles, 62(1-2), 127-137. doi: http:// dx.doi.org/10.1007/s11199-009-9703-8

Ministerio de Educación Nacional. (1999). Norma Técnica Colombiana NTC 4725 Presentación de libros de texto para preescolar. Bogotá: El Ministerio.

Ministerio de Educación Nacional(2001). Instructivo para el análisis de los libros de texto escolar. Bogotá: El Ministerio.

Ministerio de Educación Nacional (2006). Plan Sectorial de Educación 2006-2010.Bogotá, Colombia: El Ministerio.

Moctezuma, L. M. (2011). Representations of children's bodies in the Mexican textbooks, 1880-1940. ProPosições, 22(3), 35-50.

Molina, J., Devís, J. y Peiró, C. (2008). Materiales curriculares: Clasificación y uso en educación física. Pixel-Bit: Revista de Medios y Educación, (33), 183-197.

Montagnes, I. (2000) Textbooks \& learning materials 1990 1999: a global survey. International Consultative Forum on Education for All in association with the Department for International Development (United
Kingdom), ADEA Working Group on Books et Learning Materials, and the UNESCO/Danida Basic Learning Materials Initiative. Paris: UNESCO.

Moya Luque, L. (1996). Luna Lunera 1. Bogotá: Grupo Editorial Norma.

Moya, I., Ros, C., Bastida, A. y Menescardi, C. (2013). Estereotipos de sexo y raza en las imágenes de los libros de texto de educación física en primaria. Retos: Nuevas Tendencias en Educación Física, Deporte y Recreación, (23), 14-18.

Muñoz, D. \& Runge, A. (2005). Mundo de la vida, espacios pedagógicos, espacios escolares y ex-centricidad humana: Reflexiones antropológico-pedagógicas y socio-fenomenológicas. Revista Latino-americana de Ciencias Sociales, Niñez y Juventud, 3(2)

Organización Mundial de la Salud. Informe Mundial Sobre la Discapacidad. ISBN 978-92-4-068823. 2011. Malta.

Organización de las Naciones Unidas para la Educación, la Ciencia y la Cultura (UNESCO). V Declaración sobre la raza y los prejuicios raciales. Resolución de la Conferencia General, de 24 de octubre al 28 de noviembre de 1978.

Organización Mundial de la Salud (OMS). Informe Mundial Sobre la Discapacidad. ISBN 978-92-4 068823. 2011. Malta.

Oskamp, S., Kaufman, K., \& Wolterbeek, L. (1996). Gender role portrayals in preschool picture books.Journal of Social Behavior and Personality, 11(5), 27-39.

Pellejero, M. y Torres, B. (2011). La educación de la sexualidad: El sexo y el género en los libros de texto de educación primaria. Revista de Educación (354), 303-304. Navarra.

Richter, A.. \& Vaz, A. (2008). Alimentación e higiene en la rutina de la educación inicial: Calidad de vida como artificio en la instrucción de las conductas y potencialización de los hijos de la nación. Educación Física y Ciencia, (10), 77-100. Brasil: Revista Núcleo.

Ríos, M. (2003). Manual de educación física adaptada al alumnado con discapacidad. Barcelona: Paidotribo.

Sacristán Lucas, A. (1991). El currículum oculto en los textos: Una perspectiva semiótica. Revista de Educación, (296), 245-259.

Santiago, J. (2005). El cuerpo, vestido o desnudo. Versión Original: Revista De Cine, (126), 6-9. Buenos Aires Alfaguara.

Scharagrodsky, Pablo (2007). El cuerpo en la Escuela. Programa de capacitación multimedial. Buenos Aires: Ministerio de Educación, Ciencia y Tecnología.

Selander, E. (1990). Análisis de textos pedagógicos. Hacia un nuevo enfoque de la investigación educativa. Revista de Educación, (293). Pp. 345-354. La Mancha: Universidad de Castilla. 
Soler, S. (2009). La escuela y sus discursos: Los textos escolares como instrumentos de exclusión y segregación. Sociedad y Discurso, (15), 107-124. VBN: Publikation.

Taboas, M. \& Rey, A. (2012). Gender differences in physical education textbooks in spain: A content analysis of photographs.Sex Roles, 67(7-8), 389402. doi:http://dx.doi.org/10.1007/s11199-0120174-y

Terrón, M. y Cobano, V. (2008). El papel de la mujer en las ilustraciones de los libros de texto de educación primaria. Foro de Educación, (10), 385-400. España: Revista Latinoamericana de Educación.

Terrón, M. y Cobano, V. (2009). El papel de la mujer en las imágenes de los libros de texto de educación primaria. Estudio comparado entre España y Marruecos. Educatio Siglo XXI: Revista de la Facultad de Educación, (27), 231-248. España: Revista Latinoamericana de Educación.

Turner, D. (1996). Gender stereotyped descriptors in children's picture books: Does "curious jane" exist in the literature? Sex Roles, 35(7-8), 461-488.
Vaca, M. (2005). El cuerpo y la motricidad en educación inicial. el análisis de la práctica como base de la elaboración de un proyecto para el tratamiento del ámbito corporal en educación inicial. Revista Iberoamericana de Educación, (39), 207-224. España.

Vaca, M. (2007). Un proyecto para una escuela con cuerpo y en movimiento. Ágora para la Educación Física y el Deporte, (4), 91-110. España.

Yáñez, C. (2012). Representaciones sociales de las identidades en los textos escolares de ciencias sociales en Colombia. Brasil: Cadernos de Educação, (37).

Weitzman, L., Eifler, D., Hokada, E., \& Ross, C. (1972). Sex-role socialization in picture books for preschool children.American Journal of Sociology, 77(6), $1125-1150$.

Zambrini, L. (2010). “Modos de vestir e identidades de género: reflexiones sobre las marcas culturales sobre el cuerpo". En Revista de Estudios de Género Nomadías No. 1 Santiago de Chile: Universidad Nacional de Chile. 
